\title{
Registration of 'NAROSORG1 and NAROSORG3' Sorghum Varieties with High Grain Yield and Superior Grain Qualities from Uganda
}

\author{
Charles Andiku, ", Geofrey Lubadde ${ }^{2}$, Charles John Aru ${ }^{1}$, John Emanio ${ }^{1}$, Michael Adrogu Ugen ${ }^{1}$, \\ Johnie Ebiyau ${ }^{1}$
}

${ }^{1}$ National Semi-Arid Resources Research Institute (NaSARRI), Soroti, Uganda

${ }^{2}$ Department of Crop Production and Management, Faculty of Agriculture and Animal Sciences, Busitema University, Tororo, Uganda

Email address:

andikuc@gmail.com (C. Andiku)

${ }^{*}$ Corresponding author

\section{To cite this article:}

Charles Andiku, Geofrey Lubadde, Charles John Aru, John Emanio, Michael Adrogu Ugen, Johnie Ebiyau. Registration of 'NAROSORG1 and NAROSORG3' Sorghum Varieties with High Grain Yield and Superior Grain Qualities from Uganda. International Journal of Applied Agricultural Sciences. Vol. 6, No. 4, 2020, pp. 84-88. doi: 10.11648/j.ijaas.20200604.16

Received: July 27, 2020; Accepted: August 6, 2020; Published: August 20, 2020

\begin{abstract}
Sorghum [Sorghum bicolor (L.) Moench] is the third most important cereals after maize and rice in Uganda. It is mainly grown by the resource-poor rural farmers in Uganda as a staple food, but this trend has changed recently due to the gradual transition of the crop from traditional food crops to a cash crop. National Semi-Arid Resources Research Institute (NaSARRI) therefore developed and released NAROSORG1 and NAROSORG3 in 2017 with high yields and superior grain qualities for food and commercial beer production in the country. NAROSORG1 and NAROSORG3 are a selection from the International Crops Research Institute for the Semi-Arid Tropics (ICRISAT) advanced breeding lines ICSR160 and IESV92043DL respectively. Sorghum line, IESV92043DL (NAROSORG3) was bred by ICRISAT Nairobi from a cross between KARI Mtama 1 x Seredo and developed into an open-pollinated pure line variety through pedigree selection. However, the sorghum line, ICSR160 (NAROSORG1) was introduced as a Restorer or Male Parent (R-Line) for hybrid development from ICRISAT India but adapted well as a variety with very good brewing qualities for lager beer (no tannin and high extracts) production and its white-seeded variety. Performance evaluation was conducted in Uganda for two consecutive seasons of 2017 and the results showed that NAROSORG1 and NAROSORG3 had significantly higher grain yields (13.8\% and 12.2\%) and 1000 -seed weight percentages $(30.2 \%$ and $28.9 \%)$ respectively than commercial check variety, SESO1. NAROSORG1 has a good grain quality with $100 \%$ free tannin levels which is good for commercial lager beer production while NAROSORG3 had sweet juicy stalk with stay-green trait suitable for forage production in addition to good grain quality.
\end{abstract}

Keywords: Variety Registration, NAROSORG1, NAROSORG3, Evaluation, and Grain Quality

\section{Introduction}

Sorghum [Sorghum bicolor (L.) Moench] is a major cereal of the world after wheat, rice, maize, and barley however in Uganda it's the third most important cereals after maize and rice. It's mainly grown by the resource-poor rural farmers in semi-arid regions of Eastern, Northern, and South Western Uganda as a staple food [1]. The production and utilization of sorghum in Uganda have been increasing due to its ability to grow and perform under harsh environmental conditions (such as drought and low soil fertility prone areas) and its gradual transition from tradition food crop to cash crop with the assured market from the commercial beer brewing industries [2-3]. Previously in Uganda, sorghum was primarily grown for its grain as food however presently, sorghum has become an important industrial crop with a wide range of industrial purposes; including the brewing industry for making lager beers such as the Eagle and Senator lager in Uganda and beverages, starch, fortified food, food dyes, bio-energy, and syrups. In Uganda, several bottled beer brewery industries use sorghum as a substitute for imported barley for bottled beer and constitute around $40 \%$ of the 
primary ingredients and seem to be $10 \%$ cheaper compared to imported barley. This has created a viable window for sorghum production in Uganda thus bringing farmers into an agribusiness value chain [4]. In 2018, Sorghum was grown on 446,039 ha land in Uganda, producing approximately 298,252 metric tons compared to the production of 298,676 metric tons of sorghum in 373,382 ha land in 2015 [5]. The decline of about $0.14 \%$ of sorghum production in 2018 over more pieces of the land area compared to 2015 could probably be attributed to ever-changing climatic conditions in the country. The release of higher-yielding, drought-tolerant, and disease-resistant varieties with acceptable grain qualities will probably address the everlasting projected production gap of sorghum (114,000 metric tonnes) for commercial beer brewing industries in Uganda. Sorghum usage multiplied from 1,600 tons in 2003, to over 8,500 tons per annum with income-earning of over Ugandan shillings 8.7 billion. This has directly benefited around 9,000 farmers and 100,000 beneficiaries, in over 20 districts across Uganda [6]. Most of the traditionally grown sorghum varieties are landraces, which are low yielding of about $500 \mathrm{~kg} \mathrm{ha}^{-1}$ at farm level and susceptible to drought, Striga, pests and diseases, and birds [3]. This trend is still observed in the commonly grown local sorghum varieties among farmers (Andiku et al., 2019 unpublished). Therefore Ugandan farmers need high yielding variety with early to medium maturity (to avoid late-season drought) and that are resistant to Striga, shootfly, stem borer, sorghum midge, armyworm, drought, head smut, anthracnose, leaf blight, downy mildew, rust, ergot, and grain mold. Besides, it should possess high grain quality for commercial lager beer production. Consequently, National Semi-Arid Resources Research Institute (NaSARRI) released two (02) open-pollinated sorghum varieties (NAROSORG1 and NAROSORG3) with some of the fore-mentioned traits in 2017. NAROSORG1 is a high-yielding white-seeded sorghum variety with very good brewing qualities for lager beer production (no tannin and high extracts) while NAROSORG3 is drought tolerant (medium maturity) and midge resistant sorghum variety with grey seed color and has juicy sweet stalk suitable for forage with high grain yields. NAROSORG1 and NAROSORG3 are pure line varieties with desirable traits and sources of resistance to alleviate biotic and abiotic constraints sourced from the International Crops Research Institute for the Semi-Arid Tropics (ICRISAT)-Nairobi. They were tested under on-farm, multilocational, and national performance trials for wide-scale adaptation for two consecutive seasons of 2017. The multilocational testing of our materials was conducted to confirm the suitability of these materials for countrywide or specific cultivation. Therefore, understanding the response of variety to different environments is very crucial to assign the variety either to a specific or diverse environment and thus possible release to the targeted environment for production [7-8]. Hence, the main objective of this study was to evaluate the performance of promising high grain quality sorghum genotypes across the varying agro-ecologies in Uganda for possible release in the country.

\section{Materials and Methods}

\subsection{Parental Lines and Pedigree Information}

NAROSORG1 and NAROSORG3 are a selection from ICRISAT advanced breeding lines, ICSR160 and IESV 92043DL respectively and they possess critical traits such as tolerance to drought, diseases such as smut and ergot, and pests (Striga, stem borer, and midge). NAROSORG1 was introduced as a Restorer or Male Parent (R-Line) for hybrid development from ICRISAT India but adapted well as a variety with very good brewing qualities for lager beer production (no tannin and high extracts) and its white-seeded variety. However, NAROSORG3 is bred by the ICRISATNairobi, and it is an open-pollinated pure line variety derived from a cross between KARI Mtama 1 x Seredo. NAROSORG3 has been released in Somalia and Zimbabwe (by Progene Seeds Limited for Chibuku beer brewing) and has grey seed color with medium maturity and midge resistant couple with juicy sweet stalk suitable for forage.

\subsection{Breeding, Selection, and Evaluation}

Sorghum line, IESV92043DL was bred by ICRISATNairobi by crossing KARI Mtama 1 with Seredo and developed into an open-pollinated pure line through pedigree selection for drought tolerance, and midge resistance [9]. Therefore, sorghum line, IESV92043DL is an advanced sorghum variety obtained for evaluation in Uganda. While sorghum line, ICSR160 was introduced as a Restorer or Male Parent (R-Line) for hybrid development from ICRISAT-India in 2014 but adapted well as a variety with very good brewing qualities for lager beer production (no tannin and high extracts). Initially, advanced generation testing and selfing plants per line for seed increase and maintenance were conducted for three seasons on station at NaSARRI before the materials were evaluated at multi-locational and national performance trial sites for country wide adaptability. Later on-farm testing was conducted in eight (8) locations across the country to identify farmer preferences for the candidate sorghum variety (results not presented). The farmer variety preferences were based on multiple sorghum traits such as grain yield, head shape, size and compactness, grain hardiness, maturity, grain color, stay green trait, susceptibility to pests and diseases, uniformity at maturity, earliness, marketability, plant height, and vigor. Later the Distinctness, Uniformity, and Stability (DUS) tests were conducted by the Ministry of Agriculture, Animal Industry, and Fisheries (MAAIF) for two rainy seasons of 2016.

\subsection{Performance Evaluation}

Performance evaluation for yield and agronomic traits were performed for two seasons of 2017 at eight on-farm locations (Arua, Iganga, Kitgum, Mayuge, Namutumba, Oyam, Pallisa, and Serere) under rainfed conditions in Uganda using randomized complete block design with three replicates [7]. Using a plot size of $5 \mathrm{~m}$ long with four rows (inter-row and intra-row spacing of $60 \mathrm{~cm}$ and $20 \mathrm{~cm}$ 
respectively, three sorghum genotypes including commercial variety, SESO1 as a check were planted. No fertilizer was applied at any of the locations except fungicides (cypermethrin) to control shoot fly, stem borer, and midge. All the yield and agronomic data were taken from the middle two rows of the plots and the panicles with grain in the middle row were all harvested at physiological maturity. The grain yield data was first collected per plot and later extrapolated into $\mathrm{Kg} \mathrm{ha}^{-1}$ to establish grain yield per hectare [7]. Likewise, 1000 seed weight (g) was also recorded for every plot and $200 \mathrm{~g}$ seed samples were picked per plot and analyzed for brewery grain quality analysis at National Agricultural Research Laboratories (NARL-Kawanda). The tannin content was analyzed using vanillin-hydrochloric acid (V-HCl) assay of [10]. While proximate analysis for moisture and extract was carried out using the recommended method of analysis of [11]. Participatory variety selection study (results not presented), was conducted in all the trial sites (eight farmer groups) with a total of 450 farmers $(47.5 \%$ females) to assess farmers preferences for sorghum candidate varieties at physiological maturity where multiple sorghum traits as fore mentioned were used by farmers to select the best-preferred candidate sorghum varieties based on matrix ranking [12].

\subsection{Seed Maintenance and Increase}

The seeds of NAROSORG1 and NAROSORG3 were maintained and increased under in-situ and ex-situ seed conservation methods [13]. The Nucleus seed of NAROSORG1 and NAROSORG3 has been maintained at NaSARRI and some seeds have been deposited with the National Center for Genetic Resources Preservation, where it can freely be accessed for research purposes. The cultivars must be sold as a class of certified seed, by cultivar name only. Small samples of seed for research purposes may be obtained from the corresponding author.

\subsection{Statistical Analysis}

Data for each variable were analyzed using Genstat $18^{\text {th }}$ edition and the mean of each trait $\mathrm{x}_{\mathrm{i}}$ for entries was separated using the least significant difference (LSD) test.

\section{Results and Discussion}

\subsection{Agronomic and Plant Attributes at Physiological Maturity}

The agronomic and plant attributes were observed and recorded according to Sorghum descriptors [14]. NAROSORG1 (ICSR160) is a medium pure line white seeded sorghum variety (Figure 1) with the stay-green trait and has a prominent pedicel spikelet (sterile florets) during flowering compared to commercial check variety, SESO1. It has a slightly present waxy glume with a well-exerted peduncle of around 10-20 cm between the ligule of the flag leaf and the panicle base. It has an erect flag leaf with a dark green leaf blade. It also has a semi-compact and elliptic panicle of about $30-35 \mathrm{~cm}$ long with $25 \%$ glume covering and the absence of awns at physiological maturity. It is taller (around $160 \mathrm{~cm}$ ) than the commercial check variety, SESO1 with a thick stem and short internodes. NAROSORG1 is tolerant to drought however susceptible to bird damage due to sweet seeds. On average, NAROSORG1 takes 67 days to flowering and 110 days to physiological maturity with a yield range of $2800-3200 \mathrm{~kg} \mathrm{ha}^{-1}$ and has high threshability. NAROSORG1 is $100 \%$ free of tannins and suitable for lager beer production as well as confectionery; cakes, bread, and composite floor.

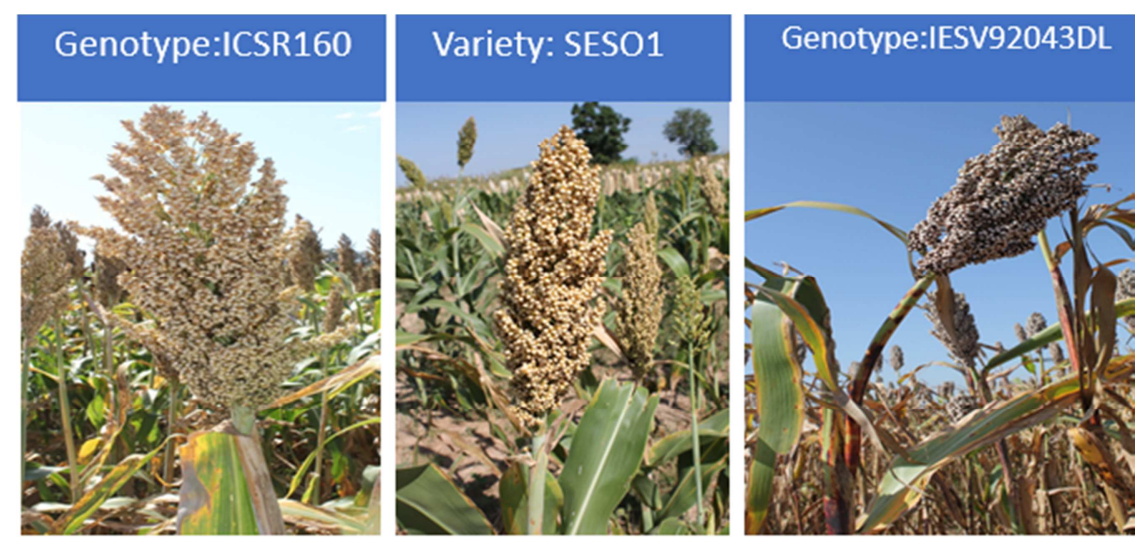

Figure 1. Panicle head of NAROSORG1, SESO1, and NAROSORG3 (Photo by U. Kyeyune).

While NAROSORG3 (IESV 92043DL) is medium open pollinated pure line variety that does not resemble any sorghum varieties currently in commercial production in Uganda. It has white Kernel color, slightly goosy (peduncle exertion sometimes curved) with semi-compact and elliptic panicle of about $20 \mathrm{~cm}$ long (Figure 1). It is grey-white sweet seeded (susceptible to bird damage) with the stay-green trait, resistant to midge, and has juicy stalk suitable for forage. It has a well-exerted peduncle of around $10-20 \mathrm{~cm}$ between the ligule of the flag leaf and the panicle base with a thick stem, semi-erect flag leaf, dark green leaf blade, and red-pigmented midrib color at maturity. NAROSORG3 has slightly waxy glumes with $25 \%$ glume covering, black glume color, and absence of awns at physiological maturity. It also has high 
threshability with a yield range of $2700-3000 \mathrm{~kg} \mathrm{ha}^{-1}$ and takes 66 days and 110 days to flowering and physiological maturity respectively with an observed medium height of about $175 \mathrm{~cm}$.

\subsection{Yield and Agronomic Attributes}

NAROSORG1 and NAROSORG3 produced a significant increase in grain yield $\left(2823 \mathrm{~kg} \mathrm{ha}^{-1}\right.$ and $\left.2783 \mathrm{~kg} \mathrm{ha}^{-1}\right)$ when tested in eight (8) locations for two seasons with a percentage yield gain of $13.8 \%$ and $12.2 \%$ respectively over SESO1 (2481 kg ha ${ }^{-1}$ ) (Table 1). Besides, NAROSORG1 and NAROSORG3 had $30.2 \%$ and $28.9 \%$ higher 1000 -seed weight than commercial check variety, SESO1 (Table 1). Grain yield, days to 50\% flowering, plant height, and 1000 seed weights were significant across the cultivars.

Table 1. Observed attributes of three (3) sorghum genotypes across eight locations.

\begin{tabular}{lllll}
\hline \multirow{2}{*}{ Cultivar } & Yield & Days to 50\% flowering & Plant height & 1000-Seed weight \\
\cline { 2 - 5 } & Kg/ha & Days & cm & gms \\
\hline NAROSORG1 & 2823 & 67 & 162.2 & 27.1 \\
NAROSORG3 & 2783 & 66 & 175.9 & 26.8 \\
SESO1 (Check) & 2481 & 62 & 145.2 & 20.8 \\
Mean & 2667 & 65 & 161.1 & 24.9 \\
LSD $(0.05)$ & $228.4 *$ & $0.836 * * *$ & $2.834 * * *$ & $0.538^{* * *}$ \\
CV & 21.1 & 3.2 & 4.3 & 5.3 \\
\hline
\end{tabular}

*Significant at the 0.05 level, and ***Significant at 0.001 level.

Plant height and days to $50 \%$ flowering ranged from 162 to $176 \mathrm{~cm}$ and $66-67$ days which is within the early to medium maturity period for released commercial varieties (Table 1). Therefore, the farmers in Uganda may benefit from growing NAROSORG1 and NAROSORG3 due to higher grain yields and relatively superior grade attributes.

\subsection{Quality Analysis}

Grain quality analysis showed that NAROSORG1 had free tannin levels of $100 \%$ with a high extract which is within acceptable ranges for production of clear beer from sorghum (Table 2). NAROSORG1 has good potential in commercial lager beer production and can be used concurrently with SESO1 which is currently used for beer production in Uganda. $78 \%$ and $54 \%$ of farmers preferred NAROSORG3 and NAROSORG1 respectively over commercial check variety, SESO1 (18\% of farmers response) during participatory variety selection study (results not presented). They mainly based their preference for NAROSORG3 on its sweet juicy stalk which is suitable for forage and other attributes. Based on these findings, NAROSORG1 and NAROSORG3 were released as pure line open-pollinated varieties in Uganda in 2017.

Table 2. Brewing grain quality analysis.

\begin{tabular}{|c|c|c|c|c|c|}
\hline \multirow{2}{*}{ Genotype } & Moisture & Extract & Extract & Free Tannin Levels & \multirow{2}{*}{ Rank } \\
\hline & $\%$ & Dry basis & Wet basis & $\%$ & \\
\hline NAROSORG1 & 11.73 & 79.3 & 70.0 & 100 & $1^{\text {st }}$ \\
\hline SESO1 (Check) & 11.79 & 78.2 & 69.0 & 99 & $2^{\text {nd }}$ \\
\hline NAROSORG3 & 12.46 & 73.5 & 65.6 & 97 & $3^{\text {rd }}$ \\
\hline
\end{tabular}

\subsection{Seed Availability}

The seeds of NAROSORG1 and NAROSORG3 have been deposited in the National Centre for Plant Genetic Resources Preservation and some small quantities of breeders seeds have been preserved at NaSARRI, P. O. Box 56 Soroti, Uganda for research purposes. Small quantities of NAROSORG1 and NAROSORG3 foundation seeds can be accessed freely for research purposes from NaSARRI however with full recognition rights to the National Agricultural Research Institute (NARO) in case of new scientific discoveries from such research activities.

\section{Conclusions}

Both sorghum varieties (NAROSORG1 and NAROSORG3) significantly out-performed the check commercial variety, SESO1 across the eight locations with a percentage yield gain of $13.8 \%$ and $12.2 \%$ respectively. NAROSORG1 is a medium white seeded sorghum variety with very superior grain qualities for lager beer production due to $100 \%$ free tannin levels and high extracts and improved composite floor nutrition. NAROSORG3 is a medium grey-white seeded sorghum variety with the staygreen trait (drought tolerant), resistant to midge, and has a juicy stalk which is suitable for forage production. Based on these unique attributes of NAROSORG1 and NAROSORG3, they were therefore released for production in the country as a pure line open-pollinated variety. Farmers in Uganda may benefit from growing these released varieties in terms of food and income security due to their superior grain qualities (cash crop for lager beer production). 


\section{Acknowledgements}

This research was supported by Harnessing Opportunities for Productivity Enhancement of Sorghum and Millets II (HOPE II) and Alliance for a Green Revolution in Africa (AGRA) Projects funded by Bill and Melinda Gates Foundation, and partly by the Government of Uganda.

\section{References}

[1] Lubadde, G., J. Ebiyau, J. C. Aru, C. Andiku, J. A. Wandulu, M. A. Ugen. (2019). SORGHUM PRODUCTION HANDBOOK FOR UGANDA. pp 37. National Semi-Arid Resources Research Institute of the National Agricultural Research Organisation (NaSARRI-NARO), Uganda.

[2] Ebiyau, J., Arach, T., \& Serunjogi, L. (2005). Commercialization of sorghum in Uganda. Paper presented at the African Crop Science Conference Proceedings.

[3] Ebiyau, J., \& Oryokot, O. (2001). Sorghum (Sorghum bicolor (L.) Moench. In: Agriculture in Uganda: Crops, Mukiibi, J. K. (Eds.). Fountain Publishers, Kampala Uganda, 2, p. 42-54.

[4] Anguzu, P. K. (2017). Employee commitment and organizational performance in Nile breweries limited Uganda. Uganda Technology and management university.

[5] FAOSTAT, F. (2018). FAOSTAT statistical database. In: Publisher: FAO (Food and Agriculture Organization of the United Nations), Rome, Italy.

[6] Nile Breweries Limited. (2016). Sustainable Development. Accessed on $20^{\text {th }}$ July 2020. Available online at http://nilebreweries.com/sustainable-development.
[7] Andiku, Charles., Lubadde, G., Aru, C., Ugen, M., \& Ebiyau, J. (2020). Additive Main Effects and Multiplicative Interaction and Genotype Main Effect and Genotype by Environment Interaction Effects-Biplot Analysis of Sorghum Grain Yield in Uganda. Journal of Agricultural Science. 12. 98 $10.5539 /$ jas.v12n6p98.

[8] Andiku, C., Tukamuhabwa, P., Ssebuliba, J. M., Talwana, H., Tumwegamire, S., \& Gruneberg, W. (2019). Evaluation of the American yam bean (Pachyrhizus spp.) for storage root yield across varying eco-geographic conditions in Uganda. doi: https://doi.org/10.5539/jas.v11n8p100.

[9] Acquaah, G. (2009). Principles of plant genetics and breeding: John Wiley \& Sons.

[10] Burns, R. E. (1971). Method for estimation of tannin in grain sorghum 1. Agronomy Journal, 63 (3), 511-512. doi: 10.2134/agronj1971.00021962006300030050x

[11] Institute of Brewing Analytical Committee (1971). Recommended methods of analysis. Journal of the Institute of Brewing, 77, 181-226.

[12] Mahesh, V., Lekshmi, P., Pawar, D. A., Kumar, A., \& Prakash, P. (2017). Matrix Ranking-An important PRA tool to assess farmers' preferences and priorities. Agricultural Science Digest-A Research Journal, 37 (2), 100-105. doi: 10.18805/asd.v37i2.7982

[13] Andiku, C., Lubadde, G., Aru, C. J., Emanio, J., Ugen, M. A., \& Ebiyau, J. (2020). Registration of 'NAROSORG2' Sorghum Variety with Desirable Farmer Attributes for Uganda, International Journal of Applied Agricultural Sciences. Vol. 6, No. 4, pp. 76-79. doi: 10.11648/j.ijaas.20200604.14.

[14] IBPGR, I. (1993). Descriptors for sorghum [Sorghum bicolor (L.) Moench]. International Board for Plant Genetic Resources, Rome, Italy. 